\title{
Revealing the Mutational Spectrum in Southern Africans With Amyotrophic Lateral Sclerosis
}

\author{
Melissa Nel, MBChB, PhD, Amokelani C. Mahungu, MSc, Nomakhosazana Monnakgotla, BSc (Hons), \\ Gerrit R. Botha, PhD, Nicola J. Mulder, PhD, Gang Wu, PhD, Evadnie Rampersaud, PhD, \\ Marka van Blitterswijk, MD, PhD, Joanne Wuu, ScM, Anne Cooley, MPH, Jason Myers, MS, \\ Rosa Rademakers, MD, PhD, J. Paul Taylor, MD, PhD, Michael Benatar, MD, PhD, and \\ Jeannine M. Heckmann, MBBCh, PhD
}

Neurol Genet 2022;8:e654. doi:10.1212/NXG.0000000000000654

\section{Abstract}

\section{Background and Objectives}

To perform the first screen of 44 amyotrophic lateral sclerosis (ALS) genes in a cohort of African genetic ancestry individuals with ALS using whole-genome sequencing (WGS) data.

\section{Methods}

One hundred three consecutive cases with probable/definite ALS (using the revised El Escorial criteria), and self-categorized as African genetic ancestry, underwent WGS using various Illumina platforms. As population controls, 238 samples from various African WGS data sets were included. Our analysis was restricted to $44 \mathrm{ALS}$ genes, which were curated for rare sequence variants and classified according to the American College of Medical Genetics guidelines as likely benign, uncertain significance, likely pathogenic, or pathogenic variants.

\section{Results}

Thirteen percent of 103 ALS cases harbored pathogenic variants; 5 different SOD1 variants (N87S, G94D, I114T, L145S, and L145F) in 5 individuals (5\%, 1 familial case), pathogenic C9orf72 repeat expansions in 7 individuals $(7 \%, 1$ familial case) and a likely pathogenic ANXA11 (G38R) variant in 1 individual. Thirty individuals (29\%) harbored $\geq 1$ variant of uncertain significance; 10 of these variants had limited pathogenic evidence, although this was insufficient to permit confident classification as pathogenic.

\section{Discussion}

Our findings show that known ALS genes can be expected to identify a genetic cause of disease in $>11 \%$ of sporadic ALS cases of African genetic ancestry. Similar to European cohorts, the 2 most frequent genes harboring pathogenic variants in this population group are C9orf 72 and SOD1.
Correspondence

Dr. Heckmann

jeanine.heckmann@uct.ac.za

From the Neurology Research Group (M.N., A.C.M., N.M., J.M.H.), Neuroscience Institute, University of Cape Town; Computational Biology Division (M.N., A.C.M., N.M., G.R.B., N.J.M.), Institute of Infectious Disease and Molecular Medicine, Cape Town, South Africa; Center for Applied Bioinformatics (G.W., E.R., J.M.), St. Jude Children's Research Hospital, Memphis, TN; Department of Neuroscience (M.v.B.), Mayo Clinic, Jacksonville, FL; Department of Neurology (J.W., A.C., M.B.), University of Miami, FL; Center for Molecular Neurology (R.R.), University of Antwerp, Belguim; Department of Cell and Molecular Biology (J.P.T.), St. Jude Children's Research Hospital, Memphis, TN; and Neurology (J.M.H.), Department of Medicine, University of Cape Town, South Africa.

Go to Neurology.org/NG for full disclosures. Funding information is provided at the end of the article.

Funding information and disclosures are provided at the end of the article. Full disclosure form information provided by the authors is available with the full text of this article at Neurology.org/NG.

The Article Processing Charge was funded by the authors.

This is an open access article distributed under the terms of the Creative Commons Attribution-NonCommercial-NoDerivatives License 4.0 (CC BY-NC-ND), which permits downloading and sharing the work provided it is properly cited. The work cannot be changed in any way or used commercially without permission from the journal. 


\section{Glossary}

ACMG = American College of Medical Genetics; AF = allele frequency; ALS = amyotrophic lateral sclerosis; $\mathbf{b p}=$ base pair; CReATe = Clinical Research in ALS and related disorders for Therapeutic Development; FTD = frontotemporal dementia; gnomAD = Genome Aggregation Database; LB = likely benign; LMN = lower motor neuron; LOF = loss of function; LP = likely pathogenic; $\mathbf{M A F}=$ minor allele frequency; PCA = principal component analysis; $\mathbf{S A C}=$ South African Coloured; UMN = upper motor neuron; VEP = variant effect predictor; VUS = variants of uncertain significance; WGS = whole-genome sequencing.

Our understanding of the epidemiologic, clinical, and genetic aspects of amyotrophic lateral sclerosis (ALS) has increased substantially due to global research efforts. Because data originate largely from Europe, North America, and Asia, very little is known about ALS in individuals with African genetic ancestry.

The reported worldwide incidence of ALS (number of new cases per 100,000 person-years) is highest in Northern Europe (1.89) and lowest in South and East Asia (0.73-0.83), whereas robust estimates of incidence rates on the African continent are unknown. ${ }^{1}$ Reports from geographical areas with populations of different genetic ancestries, such as in the United States and a small study in South Africa, ${ }^{2}$ suggest that ALS incidence rates in individuals with African ancestry are the lowest worldwide (0.56). However, underascertainment of ALS attributed to limited access to health care services and an overall younger population in developing African countries may be contributing factors.

The genetic architecture of ALS is complex and includes highly penetrant pathogenic variants and lower penetrant risk alleles, which may be present at a low background frequency in the general population. ${ }^{3}$ The former category of variants explains a high proportion of ALS cases, which segregate in families (e.g., C9orf72 pathogenic repeat expansion and pathogenic variants in SOD1), whereas lower penetrant risk alleles/variants may act in combination together with age and environmental factors consistent with an oligogenic and/or multistep basis of disease. ${ }^{3}$

Although ALS is diagnosed by clinical means, increasingly genetic testing in the form of ALS gene panel screening using next-generation sequencing may be offered to patients with ALS in developed countries. A research discovery approach is to identify rare variants in established ALS genes based on reported variant frequencies in high-resolution population databases such as the Genome Aggregation Database (gno$\mathrm{mAD}$ ) and then curate various evidence sources (ClinVar database and scientific literature) to classify them as benign or pathogenic according to the American College of Medical Genetics (ACMG) guidelines. ${ }^{4}$

Beyond the identification of known, highly penetrant pathogenic variants in causative ALS genes such as C9orf72, SOD1, FUS, and TARDBP, there is a need to systematically classify ALS-associated variants in other genes to better understand the pathogenetic mechanisms of ALS. This remains challenging due to the complex genetic architecture of ALS. First, it appears that the growing list of ALS genes (eFigure 1 and eMethods, links.lww.com/NXG/A509) seems to have unique mutational landscapes with some harboring clusters of missense variants in mutational hotspots corresponding to protein functional domains (e.g., FUS), ${ }^{5}$ whereas others harbor an excess of loss of function (LOF) variants either throughout the protein (e.g., $N E K 1)^{6}$ or in a specific region (e.g., KIF5A). ${ }^{7}$ Second, pathogenic variants in some ALS genes such as the C9orf72 expansion are found in cases of ALS, frontotemporal dementia (FTD), or a combination of both. ALS genes may be pleiotropic such as KIF5A, which also harbors variants implicated in neurologic conditions other than ALS. Lower penetrance risk alleles, which may also contribute to ALS susceptibility and/or have disease-modifying effects, may be missed by assuming that they are very rare. Determining the appropriate minor allele frequency (MAF) threshold for such variants remains a challenge. Considering these issues, it is clear that application of the ACMG guidelines ${ }^{4}$ (which were not designed for complex disorders) requires modification to adequately capture the nuances of variant classification in ALS. The dissection of the genetic underpinnings of ALS in Africans, where there is poor gene variant representation in public databases, adds an additional layer of complexity.

Apart from 2 small studies in South Africans with ALS investigating the $C 9$ orf 72 pathogenic repeat expansion frequency $^{8}$ and intermediate repeat expansion frequencies in candidate genes, which have been reported as risk alleles in Europeans, ${ }^{9}$ the genetic profile of patients with ALS with African genetic ancestry is unknown. Here, we characterized the genetic variation spectrum of African ancestry patients with ALS by screening ALS genes (based on European ancestry data) (eFigure 1 and eMethods, links.lww.com/NXG/ A509) using whole-genome sequencing (WGS) data.

\section{Methods}

\section{Patient Cohort}

We included 103 consecutive African ancestry patients with ALS attending the ALS clinic at Groote Schuur Hospital in Cape Town, South Africa, between 2014 and 2019. All patients provided informed written consent to donate a blood sample to undergo WGS. Patients were diagnosed as clinically probable or definite ALS according to the revised El Escorial 
criteria ${ }^{10}$ and categorized according to their phenotype at presentation as ALS, ALS with FTD (ALS-FTD), ${ }^{11}$ or one of the subtypes: predominantly upper motor neuron (UMN)ALS, predominantly lower motor neuron (LMN)-ALS (including flail arm/leg), and a young patient with progressive dysphagia and myopathy, dystrophic changes on muscle biopsy, who later manifested and died of ALS (labeled ALSmyopathy) (Table 1). Fifty-five (53\%) patients were men, and the overall average age at disease onset was 52.5 years. Four (4\%) patients had $\geq 1$ first-degree relative with ALS (only probands included here). All participants were of African genetic ancestry and categorized themselves according to the South African racial census categories (statssa.gov.za) as either self-assigned South African Coloured (SAC, $\mathrm{n}=76$ ) or Black African $(n=27)$. SAC refers to South Africans, mainly living in the Western Cape province, who derive their ancestry largely from Khoisan (hunter-gatherers) and Black African populations $(\sim 60 \%)$ with lesser contributions from Southeast Asians $(\sim 20 \%)$ and Europeans $(\sim 20 \%) .{ }^{12}$ The African genetic ancestry of Black African and SAC patients was verified by ancestry principal component and admixture analysis (Figure 1, eFigure 2, and eMethods, links.lww.com/NXG/ A509).

Raw data from 238 samples from various WGS data sets were included in the analysis pipeline as non-ALS population controls (referred to as in-house controls, see eFigure 3 and eMethods, links.lww.com/NXG/A509). These included 138 samples of African genetic ancestry including those from South Africa as previously described (see eMethods). The STREGA reporting guidelines were used (goodreports.org/ reporting-checklists/strega/) (eMethods).

\section{Standard Protocol Approvals, Registrations, and Patient Consents}

The study was approved by the University of Cape Town Research Ethics Committee. All patients provided informed written consent to donate a blood sample to undergo WGS.

\section{Statistical Analysis}

GraphPad Prism v9.1.0 (2016) was used to analyze the demographic and clinical data. Categorical variables were analyzed using the Fisher exact test, and for continuous variables, independent sample $t$ tests were used for normally distributed data and Mann-Whitney or 1-way analysis of variance tests for skewed data.

\section{Whole-Genome Sequencing}

WGS ( $\geq 30 \times$ coverage) with read lengths $2 \times 150$ base pair (bp) in 103 ALS cases, and between $2 \times 100$ bp or $150 \mathrm{bp}$ in 238 controls, was performed on different Illumina platforms (see eMethods, links.lww.com/NXG/A509). For consistency, the raw data (fastq files) from all patient and control samples $(\mathrm{n}=$ 341) were aligned to the NCBI GRCh38 reference genome (with alt contigs), and joint variant calling was performed according to the Genome Analysis Toolkit best practice guidelines on the Ilifu high-performance computing facility
Table 1 Characteristics of South African Patients With ALS According to the African Ancestry Group

\begin{tabular}{|c|c|c|}
\hline & \multicolumn{2}{|c|}{ African ancestry group } \\
\hline & Black $(n=27)$ & $\operatorname{SAC}(n=76)$ \\
\hline \multicolumn{3}{|l|}{ Presentation subtype, n (\%) } \\
\hline ALS & $23(85.2)$ & $53(69.7)$ \\
\hline ALS-FTD & $1(3.7)$ & $5(6.6)$ \\
\hline Predominantly UMN-ALS & $2(7.4)$ & $8(10.5)^{a}$ \\
\hline Predominantly LMN-ALS & $1(3.7)$ & $9(11.8)$ \\
\hline ALS-myopathy & 0 & $1(1.3)$ \\
\hline \multicolumn{3}{|l|}{ Region onset, n (\%) } \\
\hline Behavioral & 0 & $4(5.3)$ \\
\hline Bulbar & $2(7.4)$ & $19(25)$ \\
\hline Cervical & $11(40.7)$ & $21(27.6)$ \\
\hline Diaphragm & 0 & $2(2.6)$ \\
\hline Lumbosacral & 14 (51.9) & $30(39.5)$ \\
\hline Sex, male, n (\%) & $18(66.7)$ & $37(48.7)$ \\
\hline Age at onset, $y$, mean \pm SD & $51 \pm 11$ & $53 \pm 13$ \\
\hline \multicolumn{3}{|c|}{ Disease duration, mo, median (IQR) } \\
\hline ALS & $26(16-42)$ & $30(22-48)$ \\
\hline ALS-FTD & $96^{\mathrm{b}}$ & $63(46-95)$ \\
\hline Predominantly UMN-ALS & $78(57-68)$ & $78(46-87)$ \\
\hline Predominantly LMN-ALS & $72^{\mathrm{b}}$ & $93(43-108)$ \\
\hline ALS-myopathy & 0 & $192^{\mathrm{b}}$ \\
\hline
\end{tabular}

Abbreviations: ALS = amyotrophic lateral sclerosis; ALS-myopathy $=$ dystrophic muscle changes $+\mathrm{ALS} ; \mathrm{FTD}=$ frontotemporal dementia; $\mathrm{IQR}=$ interquartile range; $\mathrm{LMN}=$ lower motor neuron; $\mathrm{mo}=$ month; $\mathrm{SAC}=$ South African Coloured; UMN = upper motor neuron; $y=$ year.

Disease duration (survival analysis) refers to date from symptom onset to the censoring event, either date of death or last visit attended.

a One individual with familial UMN-ALS and primary progressive aphasia.

b Single patient.

(ilifu.ac.za/) using the following pipeline (github.com/grbot/ varcall). However, potential batch effects related to the use of different sequencing platforms cannot be excluded, and this is a limitation of this case-control study design.

\section{Ancestry Principal Component Analysis}

An ancestry principal component analysis (PCA) plot was constructed following single nucleotide variation (formerly single nucleotide polymorphism) pruning to extract the top 10 principal components of the variance-standardized relationship matrix (Figure 1 and eMethods, links.lww.com/NXG/A509).

\section{Standard Variant Annotation and Filtering}

To filter for rare variants, the VCF file was annotated with frequency information from gnomAD v3.1 genomes and we removed variants which were either absent or with $\mathrm{MAF}<1 \%$ 


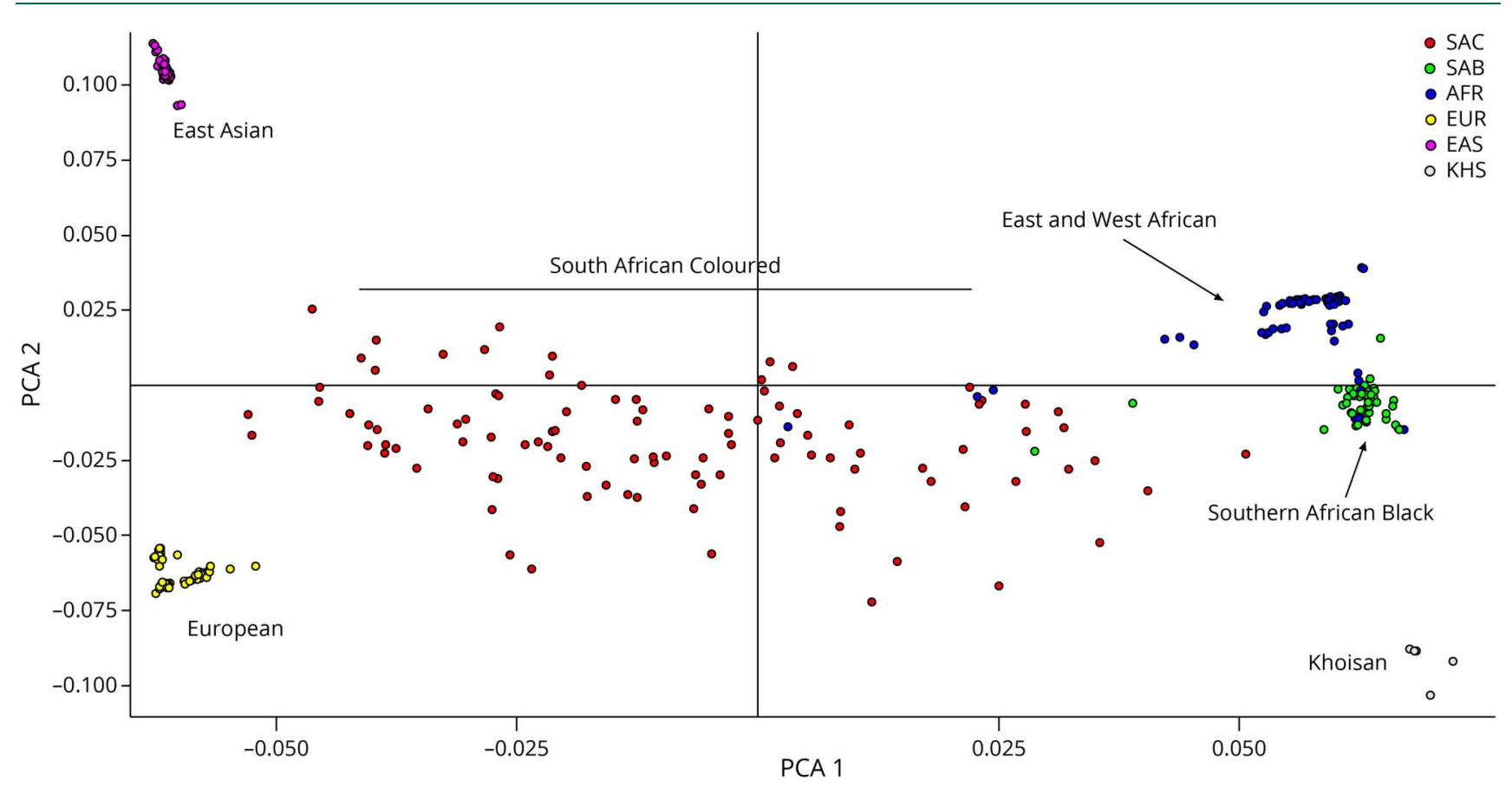

$\mathrm{ALS}=$ amyotrophic lateral sclerosis; AFR = East and West African (blue); EAS = East Asian (purple); EUR = European (yellow); KHS = Khoisan (gray); SAB = Southern African Black (green); SAC = South African Coloured (red).

in any of the 9 subpopulations in this database (Ashkenazi Jewish, South Asian, African, Other, Amish, EuropeanFinnish, East Asian, European-non-Finnish, and Ad Mixed American). In addition, variants present in any in-house controls were removed ( $1 / 476$ alleles $\sim \mathrm{MAF} 0.2 \%$ ) (eFigure 3 and eMethods, links.lww.com/NXG/A509). The Ensembl variant effect predictor (VEP) was used to annotate variants with their sequence context information, and ClinVar annotations were added from the January 28, 2021, ClinVar release (eMethods).

\section{Repeat Expansion Detection in C9orf72 and ATXN2 Genes}

For the 46 participants in the Clinical Research in ALS and related disorders for Therapeutic Development (CReATe) Consortium's Phenotype, Genotype and Biomarker study, the repeat length of the pathogenic C9orf72 GGGGCC repeat expansion was determined by the 2-step repeat-primed PCR protocol and validated by Southern blot. ${ }^{13,14}$ For the remaining patients with ALS, the Illumina ExpansionHunter v4.0.2 tool was used, and C9orf72 repeat expansions in the pathogenic range were validated by repeat-primed $\mathrm{PCR}^{8,9}$ Intermediate-length CAG repeat expansions in ATXN2 were determined by ExpansionHunter.

\section{ALS-Associated Genes}

Single nucleotide variants and insertions and deletions in 44 ALS genes (eFigure 1 and eMethods, links.lww.com/NXG/ A509) with the following VEP variant consequences were selected for further analysis $(n=62)$ : missense, inframe insertions and deletions, stop-gain, frameshift, start-lost, stoplost, splice region, splice donor, and splice acceptor with the exception of C9orf72 and ATXN2 (see eMethods, describing gene selection).

\section{Variant Classification According to ACMG Guidelines}

We classified each short variant identified in 44 ALS genes as benign, likely benign (LB), uncertain significance (variants of uncertain significance, VUS), likely pathogenic (LP), or pathogenic by applying the ACMG/AMP guidelines for the interpretation of sequence variants ${ }^{4}$ ( summarized in eTable 1 , links.lww.com/NXG/A509). Variant classification in ALS is complicated by issues such as oligogenicity, genes that may act as risk factors, and reduced penetrance of pathogenic variants. In the absence of ALS-specific variant curation guidelines, we incorporated the ClinGen Sequence Variant Interpretation working group's general use recommendations, consensus decisions from the CReATe Genetics Working Group discussions, and recently proposed guidelines. ${ }^{15}$

For each variant remaining after filtering $(n=62)$, we retrieved its allele frequency (AF) from gnom $\mathrm{AD}$ databases (v2.1.1/n = 114,704 exomes; v3.1/n = 67,442 genomes) considering only samples with nonneurologic phenotypes (eTable 1, links.lww.com/NXG/A509). Variants were reported to be absent from gnomAD if sufficient coverage $(>20 x)$ of the variant site could be confirmed by examining the integrative genomics viewer read data plots in the gno$\mathrm{mAD}$ browser. A universal MAF filter for ALS variants (both 
dominant and recessive modes of inheritance) would theoretically need to be set at around $1 \%$ to retain the SOD1 D91A variant and pathogenic C9orf72 repeat expansions, both of which have risen to appreciable background frequencies in the general population in certain bottle-necked European ancestry populations (eFigure 3 and eMethods). In contrast, the maximum credible population AF for ALS variants has been calculated at $0.01 \%$ using an online calculator (cardiodb.org/allelefrequencyapp/), which considers ALS disease-specific factors such as prevalence, genetic and allelic heterogeneity, inheritance mode, and penetrance (eFigure 3 and eMethods). ${ }^{15}$ To enable the identification of variants with reduced penetrance in risk factor genes (which may have MAF $>0.01 \%$ ), we elected to use a MAF threshold of $0.1 \% 16$ for filtering. This threshold is appropriate for our African ancestry sample which is expected to have a low likelihood of harboring pathogenic founder variations and we confirmed that the SOD1 D91A variant was absent from our data set. We also genotyped the $c 9$ orf 72 repeat expansion in each sample. Consequently, BS1 (strong benign evidence strength) was assigned where the gnom $\mathrm{AD}$ popmax filtering $\mathrm{AF}$ (or highest population $\mathrm{AF}$ if popmax unavailable) in gnom $\mathrm{AD}$ was $>0.1 \%$, whereas PM2 (supporting pathogenic evidence strength) was assigned for the remaining variants (frequency $\leq 0.1 \%$ in gnomAD). A subset of rare variants in gnomAD (PM2) exceeded 1 allele in the South African ALS sample ( $\mathrm{n}=$ 7); for these variants, we also used MAF information from a small sample of matched South African ancestry controls to interpret the rarity of these variants (eMethods).

For functional effect prediction of missense variants, we used the REVEL metapredictor score ${ }^{17}$ assigning BP4 for variants with a score $<0.5$ (predicted benign effect) and PP3 for those with a score $\geq 0.5$ (predicted deleterious effect), both at a supporting strength level. Additional detail pertaining to the application of other ACMG evidence codes is described in eMethods (links.lww.com/NXG/A509).

\section{Data Availability}

Anonymized data not published within this article will be made available by request from any qualified investigator.

\section{Results}

\section{Cohort Demographics and Phenotypes}

The demographic and clinical characteristics of 103 South Africans with ALS reflect the ancestry composition of the Western Cape province of South Africa where this study is based (Table 1). The majority (74\%) of participants had SAC genetic ancestry $(\mathrm{n}=76)$, whereas the remainder had Black African genetic ancestry $(n=27)$. Classical ALS was the most common phenotype (72\%), and the median disease duration of both UMN-ALS (78 months) and LMN-ALS cases (96 months) was significantly longer than classical ALS cases (25 months) $(p<0.0001)$.

An ancestry PCA plot representing the case and control samples included in this study $(\mathrm{n}=341)$ showed that Black Southern
Africans cluster separately from the East and West African controls in the 1000 Genomes data set (Figure 1). SAC patients and controls form a heterogeneous spread reflecting the genetic contributions from Khoisan, African, European, and Southeast Asian populations. The plot highlights the fact that the East and West African control samples in the 1000 Genomes and gno$\mathrm{mAD}$ data sets are not a suitable proxy for Southern Africans.

\section{Genetic Findings}

We identified pathogenic repeat expansions (GGGGCC repeat length $>30$ ) in the C9orf 72 gene in 7 patients (4 SAC individuals were previously reported) ${ }^{8}$ (Figure $2 \mathrm{~A}$ ) and intermediate length repeat expansions in ATXN2 (27-33 CAG repeats, classified as VUS) in 1 patient (previously reported). ${ }^{9}$ In the other ALS genes (eFigure 1 and eMethods, links.lww. com/NXG/A509), 62 variants were identified, which were classified according to ACMG evidence codes (eTable 1).

\section{LB Variants}

Eighteen of 62 variants (29\%) were classified as LB (see eTable 1, links.lww.com/NXG/A509). Seven variants were found in $>1$ patient with ALS, and 4 are South African populationspecific variations (MAF $>0.5 \%$ in AWI-GEN control data set and rarity in gnomAD). Of the $18 \mathrm{LB}$ variants, 15 have been cited in the ClinVar database with interpretations ranging from benign to VUS. Twenty-two (21\%) of African ancestry patients with ALS had a LB variant identified (Figure 2A).

\section{Variants of Uncertain Significance}

Thirty-eight of 62 variants (61\%) were classified as VUS where the cumulative evidence for a benign or pathogenic classification could not be met; 16/38 VUS have been cited in ClinVar with interpretations ranging from benign to pathogenic (eTable 1, links.lww.com/NXG/A509). For each VUS, we comprehensively assessed the overall ACMG evidence codes; 28 variants had insufficient available evidence for a pathogenic role (Table 2), whereas 10 prioritized variants had pathogenic evidence, but this was insufficient to result in a confident pathogenic classification (Table 3 and Figure 2B).

For example, TARDBP A90V may represent an ALS risk allele with reduced penetrance, and experimental studies have shown altered protein function for this variant, though not to the same degree as established pathogenic TARDBP mutants. ${ }^{18}$ Another VUS, DCTN1 E34Q is located in the CAP-gly domain of the dynactin protein together with all the reported pathogenic DCTN1 variants associated with Perry syndrome and distal hereditary motor neuropathy type 7B. However, functional studies of this variant have not shown a clear deleterious effect on dynactin protein function. ${ }^{19}$ Three different predicted LOF variants were identified in the NEK1 gene. Although interesting given the recently reported association of NEK1 LOF variants with $A L S,{ }^{6}$ the pathogenicity of these specific variants remains uncertain particularly because the background frequency of NEK1 LOF variants has not yet been established in African ancestry controls. The SQSTM1 P387A variant was highlighted as another amino acid change involving the same residue 


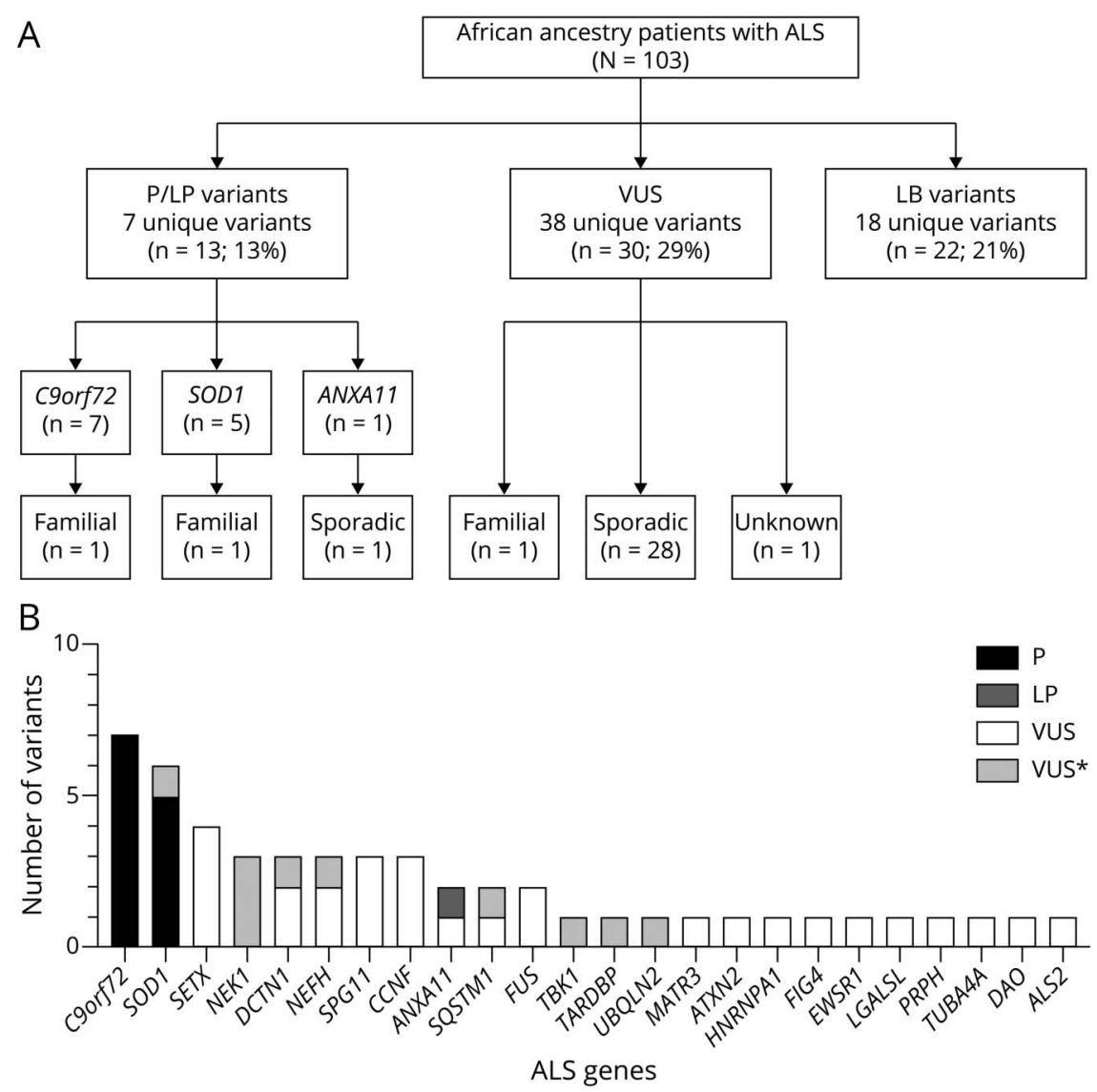

(A) Schematic showing the numbers of likely pathogenic (LP) and pathogenic (P) variants, variants of uncertain significance (VUS), and likely benign (LB) variants identified in African ancestry patients with amyotrophic lateral sclerosis (ALS). C9orf72 refers to the pathogenic C9orf72 repeat expansion. (B) Graph showing gene counts of pathogenic $(P)$ and variants of uncertain significance (VUS) in African ancestry patients with ALS. *Refers to prioritized VUS variants with a high likelihood of pathogenicity.
(P387L), which has been found in FTD cases, ${ }^{20}$ including segregation with disease in an FTD pedigree ${ }^{21}$ and incomplete penetrance in familial Paget disease, ${ }^{22}$ as well as 2 reports of impact on protein function. ${ }^{23,24} \mathrm{NEFH}$ N390T has been described in a case of FTD. ${ }^{25}$ UBQLN2 P525S has been reported in FTD families with incomplete penetrance, ${ }^{26,27}$ but functional studies report conflicting results for this variant. ${ }^{28-30}$ TBK1 R134H has been reported in a patient with ALS, ${ }^{31}$ and functional studies suggest that this variant alters protein function. ${ }^{32}$ SOD1 D97E involves the same amino acid described in a recessive ALS family where affected individuals carry heterozygous SOD1 D97N and D91A (or D90A) variants. ${ }^{33}$

\section{LP and Pathogenic Variants}

The LP ANXA11 G38R variant (Table 3) has been reported in 5 cases with ALS, ${ }^{34-36} 2$ of which had prominent spasticity and associated cognitive impairment/FTD, similar to our case. Furthermore, 1 of these ALS cases showed typical ALS neuropathology in the spinal cord and TDP-43 pathology in the cortex. $^{36}$ The benign REVEL score reported for this variant conflicts with both the neuropathologic evidence and the functional studies, which show altered protein function. ${ }^{34,36-38}$ Although gene curation is performed in an unbiased manner, the clinical milieu is considered in the final step; we found the SOD1 D97E and ANXA11 G38R variants in a single individual with prominent spasticity and increasing behavioral dysfunction for 3-4 years before presenting with ALS.

We identified 5 different pathogenic SOD1 variants (REVEL scores 20.85 ) in exons 4 (N87S, G94D, and I114T) and 5 (L145S and L145F) of the SOD1 protein (Table 3). The SOD1 L145F variant was in an LMN-ALS case with a family history and confirmed in 2 siblings (not included in the WGS analysis). The individual with SOD1 G94D also had predominantly LMNALS onset, whereas ALS presentations occurred in those with SOD1 I114T and L145S, and another with SOD1 N87S had early diaphragmatic involvement and died within 8 months.

In the 44 ALS genes examined in this study, 24 harbored pathogenic variants and/or VUS (Figure 2B) in African ancestry patients. Pathogenic and LP variants were identified in 13/103 (13\%) individuals: pathogenic C9orf72 repeat expansions (7\%), SOD1 (5\%), and ANXA11 (1\%), whereas 38 VUS were identified in 30/103 individuals (29\%) (Figure 2A). All 11 SAC patients harboring pathogenic and LP variants were determined to have a proportion of African genetic ancestry by admixture analysis (eFigure 2 in eMethods, links.lww.com/ NXG/A509). The C9orf72 and SOD1 carrier frequencies did not differ when patients with a family history of ALS or no available family history data were excluded (Figure 2A). 
Table 2 Variants of Uncertain Significance Identified in ALS Genes in South Africans With ALS With Insufficient Available Evidence for Pathogenic Role

\begin{tabular}{|c|c|c|c|c|}
\hline Gene (HGVSp) & Variant class & gnomAD v2.1.1; v3.1 & REVEL & ClinVar \\
\hline ALS2 V1183M ${ }^{\mathrm{a}}$ & Missense & $5.7 \mathrm{E}-4 ; 5.0 \mathrm{E}-4$ & 0.08 & VUS $^{\mathrm{b}}$ \\
\hline TUBA4A G45A & Missense & 2.0E-4; absent & 0.16 & - \\
\hline LGALSL R106K & Missense & $3.7 \mathrm{E}-6 ; 1.6 \mathrm{E}-5$ & 0.10 & - \\
\hline DCTN1 E1187Q & Missense & Absent & 0.29 & - \\
\hline DCTN1 S1112T & Missense & Absent & 0.14 & - \\
\hline MATR3 H337R & Missense & $9.0 \mathrm{E}-4 ; 6.8 \mathrm{E}-4$ & 0.28 & $\mathrm{LB}^{\mathrm{b}}$ \\
\hline SQSTM1 A2V & Missense & $4.3 \mathrm{E}-5 ; 2.6 \mathrm{E}-4$ & 0.04 & VUS $^{b}$ \\
\hline FIG4 V57D & Missense & Absent & 0.38 & VUS $^{\mathrm{b}}$ \\
\hline SETX L2473V & Missense & $1.3 \mathrm{E}-4 ; 7.3 \mathrm{E}-5$ & 0.28 & VUS $^{\mathrm{b}}$ \\
\hline SETX I1830M ${ }^{a}$ & Missense & Absent; $6.8 \mathrm{E}-5$ & 0.17 & - \\
\hline SETX $\mathrm{P} 1464 \mathrm{~S}$ & Missense & $2.9 \mathrm{E}-5 ; 8.0 \mathrm{E}-6$ & 0.20 & VuS $^{b}$ \\
\hline SETX N762Y & Missense & 1.1E-5; absent & 0.23 & - \\
\hline ANXA11 S301C & Missense & Absent; 8.0E-6 & 0.63 & - \\
\hline PRPH A304V & Missense & 3.3E-5; absent & 0.68 & - \\
\hline HNRNPA1 N245D & Missense & Absent & 0.36 & - \\
\hline DAO P103L & Missense (sp/r) & $2.8 \mathrm{E}-3 ; 1.6 \mathrm{E}-3$ & 0.44 & $\mathrm{LB}^{\mathrm{b}}$ \\
\hline SPG11 M2132T & Missense & $6.0 \mathrm{E}-5 ; 5.0 \mathrm{E}-4$ & 0.76 & VUS $^{\mathrm{b}}$ \\
\hline SPG11 R1196H & Missense & $8.9 \mathrm{E}-6 ; 1.2 \mathrm{E}-5$ & 0.43 & VUS $^{c}$ \\
\hline SPG11 R848K & Missense & 2.6E-5; 2.1E-4 & 0.08 & - \\
\hline SPG11 K638R & Missense & $2.3 \mathrm{E}-4 ; 2.0 \mathrm{E}-4$ & 0.09 & VUS $^{\mathrm{b}}$ \\
\hline CCNF Y341F & Missense & 9.2E-4; 7.9E-4 & 0.18 & - \\
\hline CCNF G556R & Missense & Absent & 0.06 & - \\
\hline CCNF P756L & Missense & 3.0E-4; 5.4E-4 & 0.01 & - \\
\hline FUS R216C & Missense & $2.9 \mathrm{E}-4 ; 1.4 \mathrm{E}-3$ & 0.68 & $\mathrm{P}$ \\
\hline FUS R274C & Missense & 3.7E-6; absent & 0.11 & - \\
\hline EWSR1 P180S & Missense & Absent & 0.57 & - \\
\hline NEFH G86S & Missense & $2.0 \mathrm{E}-4 ; 2.0 \mathrm{E}-4$ & 0.22 & - \\
\hline NEFH K525N & Missense & 4.2E-4; 1.9E-4 & 0.22 & VUS $^{\mathrm{b}}$ \\
\hline
\end{tabular}

Abbreviations: ACMG = American College of Medical Genetics; ALS = amyotrophic lateral sclerosis; gnomAD = Genome Aggregation Database; HGVSp = Human Genome Variation Society protein nomenclature; LB = likely benign; NA = not applicable; P = pathogenic; VUS = variants of uncertain significance. Classification according to ACMG codes as variants of uncertain significance. HGVSp refers to the Human Genome Variation Society protein nomenclature to describe sequence variants. gnomAD v2.1.1 and v3.1 refer to frequency data from the nonneuro subsets (gnomad.broadinstitute.org). REVEL refers to the metapredictor score. All variants were heterozygous singletons and not found in a sample of 100 Black South African controls (see eMethods, links.Iww.com/ NXG/A509); this information is included for 2 rare variants in gnomAD but found in 2 ALS cases (indicated by ${ }^{a}$ ). The ClinVar review status of a record on September 8, 2021, is indicated as follows: ${ }^{b}$ criteria provided, single submitter/conflicting interpretations; ${ }^{c}$ criteria provided, multiple submitters, no conflicts; no stars = no assertion criteria provided. ACMG evidence codes and comments about available evidence and references are described in eTable 1.

\section{Discussion}

In this report, we describe the genetic variation spectrum in a sample of patients with ALS from the Western Cape region of South Africa using a virtual ALS gene screen of WGS data. Although these patients had African ancestry, they comprised predominantly the SAC ancestry group (74\%), whereas Black Africans represented $26 \%$ of our patients. The frequency of LP and pathogenic variants in this African ancestry ALS cohort without a family history of ALS (11/100; $11 \%)$ was lower than a similar-sized European ancestry cohort with sporadic ALS (15/93, 16\%), ${ }^{16}$ although the 2 most frequent genes 
Table 3 ALS Gene Variants in 103 South Africans With ALS That Have Either Potential or Definite Pathogenic Roles as Curated by ACMG Evidence Codes

\begin{tabular}{|c|c|c|c|c|}
\hline Gene variant (HGVSp) & Variant class & gnomAD v2.1.1; v3.1 & REVEL & ClinVar \\
\hline \multicolumn{5}{|c|}{ A: VUS with a potential pathogenic role in ALS } \\
\hline TARDBP A90V & Missense & $3.5 \mathrm{E}-4 ; 4.2 \mathrm{E}-4$ & 0.17 & VUS $^{a}$ \\
\hline DCTN1 E34Q & Missense & $6.9 \mathrm{E}-5 ; 5.8 \mathrm{E}-5$ & 0.77 & VUS $^{a}$ \\
\hline NEK1 D997AfsTer8 & Frameshift & Absent & NA & - \\
\hline NEK1 K580RfdTer19 & Frameshift & Absent & NA & - \\
\hline NEK1 E195Ter & Stop gained & Absent & NA & - \\
\hline SQSTM1 P387A & Missense & $1.1 \mathrm{E}-5 ; 1.6 \mathrm{E}-5$ & 0.66 & - \\
\hline TBK1 R134H & Missense & $3.0 \mathrm{E}-6 ; 1.6 \mathrm{E}-5$ & 0.73 & - \\
\hline SOD1 D97E & Missense & $6.2 \mathrm{E}-5 ; 3.1 \mathrm{E}-5$ & 0.31 & - \\
\hline NEFH N390T & Missense & 4.0E-4; 1.7E-4 & 0.84 & $\mathrm{VUS}^{\mathrm{b}}$ \\
\hline UBQLN2 P525S & Missense & $8.2 \mathrm{E}-3 ; 6.2 \mathrm{E}-6$ & 0.53 & $\mathrm{~B} / \mathrm{LB} / \mathrm{VUS} \mathrm{S}^{\mathrm{b}}$ \\
\hline \multicolumn{5}{|c|}{ B: Variants classified as LP } \\
\hline ANXA11 G38R & Missense & $3.9 \mathrm{E}-5 ; 3.8 \mathrm{E}-5$ & 0.26 & $\mathrm{P}$ \\
\hline \multicolumn{5}{|c|}{ C: Variants classified as pathogenic } \\
\hline SOD1 N87S & Missense & Absent & 0.85 & $P / L P^{a}$ \\
\hline SOD1 G94D & Missense & Absent & 0.91 & $\mathrm{P}^{\mathrm{b}}$ \\
\hline SOD1 I114T & Missense & 1.1E-5; $1.6 \mathrm{E}-5$ & 0.99 & $P^{a}$ \\
\hline SOD1 L145S & Missense & Absent & 0.96 & $P^{a}$ \\
\hline SOD1 L145F & Missense & Absent & 0.92 & $\mathrm{P}^{\mathrm{a}}$ \\
\hline
\end{tabular}

Abbreviations: $A C M G=$ American College of Medical Genetics; ALS = amyotrophic lateral sclerosis; $B=$ benign; gnomAD = Genome Aggregation Database; HGVSp = Human Genome Variation Society protein nomenclature; LB = likely benign; $L P=$ likely pathogenic; $N A=$ not applicable; $P=$ pathogenic; VUS = variants of uncertain significance.

Classification according to ACMG codes as (A) variants of uncertain significance with a potential pathogenic role in ALS, (B) LP variants, and (C) variants with an established pathogenic role in ALS. HGVSp refers to the Human Genome Variation Society protein nomenclature to describe sequence variants. gnomAD v2.1.1 and v3.1 refer to frequency data from the nonneuro subsets (gnomad.broadinstitute.org). REVEL refers to the metapredictor score. All variants were heterozygous singletons. The ClinVar review status of a record on September 8, 2021, is indicated as follows: ${ }^{\mathrm{a}}$ criteria provided, multiple submitters, no conflicts; ${ }^{b}$ criteria provided, single submitter/conflicting interpretations; no stars = no assertion criteria provided. ACMG evidence codes and comments about available evidence and references are described in eTable 1 (links.IwW.com/NXG/A509).

harboring pathogenic variants in both cohorts were C9orf72 and SOD1.

A pathogenic hexanucleotide repeat expansion $(>30)$ in the noncoding region of the $C 9$ orf 72 is the most common pathogenic genetic variant in ALS/FTD identified to date. ${ }^{13,14}$ This finding was replicated in our African ancestry cohort where we found a C9orf72 pathogenic expansion carrier frequency of $6.8 \%$ (7.9\% in SAC and 3.7\% in Black patients), which does not differ substantially from reported frequencies among sporadic ALS cases with European genetic ancestry $(5.1 \%-7 \%){ }^{16}$ Pathogenic SOD1 variants the next most frequently identified in Europeans with ALS (1.2\%), ${ }^{16}$ were found in $4 \%$ of African ancestry patients without a family history of ALS. We identified I114T (or I113T) in 1 SAC individual, which is the most common pathogenic SOD1 variant in patients with ALS in the United Kingdom, ${ }^{16}$ but did not observe D91A (the most common pathogenic variant worldwide) and $\mathrm{A} 5 \mathrm{~V}$ (the most common pathogenic variant in North America). Although the sample size is small, our findings suggest that pathogenic SOD1 variants are an important genetic cause of ALS in African ancestry populations, at least in Southern Africa.

Variant curation efforts in ALS are already challenging due to the complex genetic architecture of the disease while gene panel testing for ALS in African genomes may pose additional challenges due to ancestry-related bias. African genomes are highly diverse as a result of their ancient origins. A significant proportion of this variation is either novel (not represented in high-resolution population genetic databases such as gnomAD, which lack Southern African samples) or misclassified (as VUS or pathogenic variants in the ClinVar database when they in fact represent benign African-specific variations). For example, $33 \%(6 / 18)$ of the rare variants we curated as LB according to ACMG evidence codes were classified as VUS in the ClinVar database. 
In this African ancestry ALS cohort, 29\% harbored $\geq 1$ VUS, which is comparable to reported frequencies in a British cohort of similar size (23\%). ${ }^{16}$ The pathogenicity of the 10 variants identified in African ancestry samples, which we prioritized for future research (Table 2), could be questioned on the grounds of population AF (MAF $>0.1 \%$ ), reports of genotype-phenotype discordance within previously studied families (incomplete penetrance), and benign predictions by computational tools, which are in conflict with functional studies. However, it has been shown that the AF of pathogenic variants related to later adult-onset dominant diseases is higher compared with those related to earlier-onset dominant diseases as they are not subject to the same selective pressures. ${ }^{39}$ It is also recognized that intrafamilial genetic heterogeneity, shared de novo or epivariations and pleiotropy may explain the genotype-phenotype discordance, which is not infrequently observed in ALS families. ${ }^{40}$ Consequently, the task of variant curation in ALS should consider that the genetic basis of this disease exists on a spectrum from monogenic (excessively rare, highly penetrant variants) to oligogenic (higher frequency risk factor variants requiring one or more second hits, which may be genetic or environmental). It is therefore unlikely that universal application of filtering thresholds will be adequate to capture variants at both extremes of this genetic spectrum.

In conclusion, an ALS gene screen in African ancestry patients with ALS, without a family history of ALS, yielded a pathogenic variant (C9orf72, SOD1, or ANXA11) in 11\% of cases. This highlights the proportion of Africans with ALS who would benefit from genetic testing and would be eligible for gene therapy trials, which are already underway for patients carrying pathogenic SOD1 and C9orf 72 variants. Although this study highlights challenges for the clinical interpretation of sequence variants in patients with ALS of African genetic ancestry, ALS cohorts from Africa should be included in large-scale ALS gene discovery efforts.

\section{Acknowledgment}

The authors thank Dr. C. Albertyn for cognitive phenotyping of the ALS cases. The authors thank the Africa WitsINDEPTH partnership for Genomics studies (AWI-Gen), a Human Heredity and Health in Africa (H3A) Consortium study, for providing variant frequency information for South African control subjects. The authors also thank the Southern African Human Genome Programme (SAHGP) participants. The South African WGS data set was generated by the national SAHGP initiative funded by the Department of Science and Technology of South Africa. The authors acknowledge the use of the Ilifu cloud computing facility (ilifu.ac.za), a partnership between the University of Cape Town, the University of the Western Cape, the University of Stellenbosch, Sol Plaatje University, the Cape Peninsula University of Technology, and the South African Radio Astronomy Observatory. The Ilifu facility is supported by contributions from the Inter-University Institute for Data Intensive Astronomy (IDIA-a partnership between the
University of Cape Town, the University of Pretoria, and the University of the Western Cape), the Computational Biology division at UCT, and the Data Intensive Research Initiative of South Africa (DIRISA). JMH and AM receive funding from the National Research Foundation of South Africa. MN is the recipient of a CReATe scholar award and a Carnegie Developing Emerging Academic Leaders (DEAL) award. This publication was made possible (in part) by a grant from Carnegie Corporation of New York and a L'Oréal-UNESCO For Women in Science South African Young Talents Award. The statements made and views expressed are solely the responsibility of the authors.

\section{Study Funding}

The authors acknowledge the support of Nicola Mulder's group who funded the whole-genome sequencing of $25 \mathrm{ALS}$ cases (Human Genome Research Institute: U24HG006941). They thank the CReATe consortium and Paul Taylor's laboratory at St Jude's funded by Amyotrophic Lateral Sclerosis Association (ALSA) and St Jude American Lebanese Syrian Associated Charities (ALSAC). The Clinical Research in ALS and related disorders for Therapeutic Development (CReATe) Consortium (U54NS092091) is part of Rare Diseases Clinical Research Network (RDCRN), an initiative of the Office of Rare Diseases Research (ORDR), National Center for Advancing Translational Sciences (NCATS). This consortium is funded through collaboration between NCATS and the NINDS.

\section{Disclosure}

The authors report no disclosures relevant to the manuscript. Go to Neurology.org/NG for full disclosures.

\section{Publication History}

Received by Neurology: Genetics October 1, 2021. Accepted in final form December 8, 2021.

Appendix Authors

\begin{tabular}{|c|c|c|}
\hline Name & Location & Contribution \\
\hline $\begin{array}{l}\text { Melissa Nel, } \\
\text { MBChB, PhD }\end{array}$ & $\begin{array}{l}\text { Neurology Research } \\
\text { Group, Neuroscience } \\
\text { Institute, University of } \\
\text { Cape Town; } \\
\text { Computational Biology } \\
\text { Division, Institute of } \\
\text { Infectious Disease and } \\
\text { Molecular Medicine, Cape } \\
\text { Town, South Africa }\end{array}$ & $\begin{array}{l}\text { Drafting/revision of the } \\
\text { manuscript for content, } \\
\text { including medical writing } \\
\text { for content; major role in } \\
\text { the acquisition of data; } \\
\text { study concept or design; } \\
\text { and analysis or } \\
\text { interpretation of data }\end{array}$ \\
\hline $\begin{array}{l}\text { Amokelani C. } \\
\text { Mahungu, MSc }\end{array}$ & $\begin{array}{l}\text { Neurology Research } \\
\text { Group, Neuroscience } \\
\text { Institute, University of } \\
\text { Cape Town; } \\
\text { Computational Biology } \\
\text { Division, Institute of } \\
\text { Infectious Disease and } \\
\text { Molecular Medicine, Cape } \\
\text { Town, South Africa }\end{array}$ & $\begin{array}{l}\text { Drafting/revision of the } \\
\text { manuscript for content, } \\
\text { including medical writing } \\
\text { for content, and analysis } \\
\text { or interpretation of data }\end{array}$ \\
\hline
\end{tabular}

Continued 
Appendix (continued)

\begin{tabular}{|c|c|}
\hline Name & Location \\
\hline $\begin{array}{l}\text { Nomakhosazana } \\
\text { Monnakgotla, } \\
\text { BSc (Hons) }\end{array}$ & $\begin{array}{l}\text { Neurology Research } \\
\text { Group, Neuroscience } \\
\text { Institute, University of } \\
\text { Cape Town; } \\
\text { Computational Biology } \\
\text { Division, Institute of } \\
\text { Infectious Disease and } \\
\text { Molecular Medicine, Cape } \\
\text { Town, South Africa }\end{array}$ \\
\hline
\end{tabular}

\begin{tabular}{lll}
\hline Gerrit R. Botha, & $\begin{array}{l}\text { Computational Biology } \\
\text { PhD }\end{array}$ & $\begin{array}{l}\text { Major role in the } \\
\text { Infectious Disease and }\end{array}$ \\
& $\begin{array}{l}\text { acquisition of data and } \\
\text { analysis or interpretation } \\
\text { Town, South Africa }\end{array}$ & \\
&
\end{tabular}

\begin{tabular}{|c|c|c|}
\hline $\begin{array}{l}\text { Nicola J. Mulder, } \\
\text { PhD }\end{array}$ & $\begin{array}{l}\text { Computational Biology } \\
\text { Division, Institute of } \\
\text { Infectious Disease and } \\
\text { Molecular Medicine, Cape } \\
\text { Town, South Africa }\end{array}$ & $\begin{array}{l}\text { Major role in the } \\
\text { acquisition of data and } \\
\text { analysis or interpretation } \\
\text { of data }\end{array}$ \\
\hline
\end{tabular}

Gang Wu, PhD Center for Applied Bioinformatics, St. Jude manuscript for content Children's Research including medical writing Hospital, Memphis, TN for content; study concept or design; and analysis or interpretation of data

\begin{tabular}{ll}
\hline Evadnie & Center for Applied \\
Rampersaud, & Bioinformatics, St. Jude \\
PhD & Children's Research
\end{tabular}

Drafting/revision of the manuscript for content, including medical Hospital, Memphis, TN writing for content; study concept or design; and analysis or interpretation of data

\begin{tabular}{ll}
\hline Marka van & Department of \\
Blitterswijk, MD, & Neuroscience, Mayo \\
PhD & Clinic, Jacksonville, FL
\end{tabular}

Major role in the acquisition of data; study concept or design; and analysis or interpretation of data

Joanne Wuu, ScM Department of Neurology, Major role in the University of Miami, FL acquisition of data; study concept or design; and analysis or interpretation of data

\begin{tabular}{lll}
\hline Anne Cooley, & Department of Neurology, \\
MPH & University of Miami, FL & $\begin{array}{l}\text { Major role in the } \\
\text { acquisition of data; and } \\
\text { study supervision or } \\
\text { coordination }\end{array}$
\end{tabular}

Jason Myers, MS Center for Applied Bioinformatics, St. Jude Children's Research Hospital, Memphis, TN

Drafting/revision of the manuscript for content, including medical writing for content, and analysis or interpretation of data

\begin{tabular}{ll}
\hline Rosa & Center for Molecular \\
Rademakers, & Neurology, University of \\
MD, PhD & Antwerp, Belguim
\end{tabular}

Drafting/revision of the manuscript for content, including medical writing for content, and major role in the acquisition of data

\begin{tabular}{lll}
\hline J. Paul Taylor, & Department of Cell and & Drafting/revision of the \\
MD, PhD & Molecular Biology, St. Jude & manuscript for content, \\
Children's Research & including medical \\
Hospital, Memphis, TN & $\begin{array}{l}\text { writing for content; } \\
\text { study concept or design; } \\
\end{array}$ & $\begin{array}{l}\text { and analysis or } \\
\text { interpretation of data }\end{array}$ \\
& \\
\end{tabular}

Appendix (continued)

\begin{tabular}{|c|c|c|}
\hline Name & Location & Contribution \\
\hline $\begin{array}{l}\text { Michael Benatar, } \\
\text { MD, PhD }\end{array}$ & $\begin{array}{l}\text { Department of Neurology, } \\
\text { University of Miami, FL }\end{array}$ & $\begin{array}{l}\text { Drafting/revision of the } \\
\text { manuscript for content, } \\
\text { including medical writing } \\
\text { for content; major role in } \\
\text { the acquisition of data; } \\
\text { study concept or design; } \\
\text { and analysis or } \\
\text { interpretation of data }\end{array}$ \\
\hline $\begin{array}{l}\text { Jeannine M. } \\
\text { Heckmann, } \\
\text { MBBCh, PhD }\end{array}$ & $\begin{array}{l}\text { Neurology Research } \\
\text { Group, Neuroscience } \\
\text { Institute, University of } \\
\text { Cape Town; Neurology, } \\
\text { Department of Medicine, } \\
\text { University of Cape Town, } \\
\text { Cape Town, South Africa }\end{array}$ & $\begin{array}{l}\text { Drafting/revision of the } \\
\text { manuscript for content, } \\
\text { including medical writing } \\
\text { for content; major role in } \\
\text { the acquisition of data; } \\
\text { study concept or design; } \\
\text { and analysis or } \\
\text { interpretation of data }\end{array}$ \\
\hline
\end{tabular}

\section{References}

1. Marin B, Boumé diene F, Logroscino G, et al. Variation in world wide incidence of amyotrophic lateral sclerosis: a meta-analysis. Int J Epidemiol. 2017;46(1):57-74. doi: $10.1093 / \mathrm{ije} /$ dyw061.

2. Henning F, Heckmann JM, Naidu K, Vlok L, Cross HM, Marin B. Incidence of motor neuron disease/amyotrophic lateral sclerosis in South Africa: a 4-year prospective study. Eur J Neurol. 2021;28(1):81-89. doi: 10.1111/ene.14499.

3. Shatunov A, Al-Chalabi A. The genetic architecture of ALS. Neurobiol Dis. 2021;147: 105156. doi: 10.1016/j.nbd.2020.105156.

4. Richards S, Aziz N, Bale S, et al. Standards and guidelines for the interpretation of sequence variants: a joint consensus recommendation of the American College of Medical Genetics and Genomics and the Association for Molecular Pathology. Genet Med. 2015;17(5):405-424. doi: 10.1038/gim.2015.30.

5. Kwiatkowski TJ, Bosco DA, Leclerc AL, et al. Mutations in the FUS/TLS gene on chromosome 16 cause familial amyotrophic lateral sclerosis. Science. 2009;323(5918): 1205-1208. doi: 10.1126/science.1166066.

6. Kenna KP, Van Doormaal PTC, Dekker AM, et al. NEK1 variants confer susceptibility to amyotrophic lateral sclerosis. Nat Genet. 2016;48(9):1037-1042. doi: 10.1038/ ng.3626.

7. Nicolas A, Kenna KP, Renton AE, et al. Genome-wide analyses identify KIF5A as a novel ALS gene. Neuron. 2018;97(6):1268-1283.e6. doi: 10.1016/j.neuron.2018.02.027.

8. Nel M, Agenbag GM, Henning F, Cross HM, Esterhuizen A, Heckmann JM. C9orf72 repeat expansions in South Africans with amyotrophic lateral sclerosis. J Neurol Sci. 2019;401:51-54. doi: 10.1016/j.jns.2019.04.026.

9. Nel M, Mavundla T, Gultig K, et al. Repeats expansions in ATXN2, NOP56, NIPA1 and ATXN1 are not associated with ALS in Africans. IBRO Neurosci Rep. 2021;10: 130-135. doi: 10.1016/j.ibneur.2021.02.002.

10. Brooks BR, Miller RG, Swash M, Munsat TL. El Escorial revisited: revised criteria for the diagnosis of amyotrophic lateral sclerosis. Amyotroph Lateral Scler. 2000;1(5): 293-299. doi: 10.1080/146608200300079536.

11. Strong MJ, Abrahams S, Goldstein LH, et al. Amyotrophic lateral sclerosisfrontotemporal spectrum disorder (ALS-FTSD): revised diagnostic criteria. Amyotroph Lateral Scler Front Degener. 2017;18(3-4):153-174. doi: 10.1080/ 21678421.2016.1267768.

12. De Wit E, Delport W, Rugamika CE, et al. Genome-wide analysis of the structure of the South African Coloured population in the Western Cape. Hum Genet. 2010; 128(2):145-153. doi: 10.1007/s00439-010-0836-1.

13. DeJesus-Hernandez M, Mackenzie IR, Boeve BF, et al. Expanded GGGGCC hexanucleotide repeat in noncoding region of C9ORF72 causes chromosome 9p-linked FTD and ALS. Neuron. 2011;72(2):245-256. doi: 10.1016/j.neuron.2011.09.011.

14. Renton AE, Majounie E, Waite A, et al. A hexanucleotide repeat expansion in C9ORF72 is the cause of chromosome 9p21-linked ALS-FTD. Neuron. 2011;72(2): 257-268. doi: 10.1016/j.neuron.2011.09.010.

15. Lattante S, Marangi G, Doronzio PN, et al. High-throughput genetic testing in ALS: the challenging path of variant classification considering the ACMG guidelines. Genes (Basel). 2020;11(10):1123. doi: 10.3390/genes11101123.

16. Shepheard SR, Parker MD, Cooper-Knock J, et al. Value of systematic genetic screening of patients with amyotrophic lateral sclerosis. J Neurol Neurosurg Psychiatry. 2021;92(5):510-518. doi: 10.1136/jnnp-2020-325014.

17. Ioannidis NM, Rothstein JH, Pejaver V, et al. REVEL: an ensemble method for predicting the pathogenicity of rare missense variants. Am J Hum Genet. 2016;99(4): 877-885. doi: 10.1016/j.ajhg.2016.08.016.

18. Wobst HJ, Wesolowski SS, Chadchankar J, et al. Cytoplasmic relocalization of TAR DNA-binding protein 43 is not sufficient to reproduce cellular pathologies associated with ALS in vitro. Front Mol Neurosci. 2017;10:46. doi: 10.3389/ fnmol.2017.00046. 
19. Stockmann M, Meyer-Ohlendorf $\mathrm{M}$, Achberger $\mathrm{K}$, et al. The dynactin $\mathrm{p} 150$ subunit: cell biology studies of sequence changes found in ALS/MND and Parkinsonian Syndromes. J Neural Transm. 2013;120(5):785-798. doi: 10.1007/s00702-012-0910-z.

20. van der Zee J, Van Langenhove T, Kovacs GG, et al. Rare mutations in SQSTM1 modify susceptibility to frontotemporal lobar degeneration. Acta Neuropathol. 2014; 128(3):397-410. doi: 10.1007/s00401-014-1298-7.

21. Le Ber I. SQSTM1 mutations in French patients with frontotemporal dementia or frontotemporal dementia with amyotrophic lateral sclerosis. JAMA Neurol. 2013; 70(11):1403-1410. doi: 10.1001/jamaneurol.2013.3849.

22. Johnson-Pais TL, Wisdom JH, Weldon KS, et al. Three novel mutations in SQSTM1 identified in familial Paget's disease of bone. J Bone Miner Res. 2003;18(10): 1748-1753. doi: 10.1359/jbmr.2003.18.10.1748.

23. Cavey JR, Ralston SH, Sheppard PW, et al. Loss of ubiquitin binding is a unifying mechanism by which mutations of SQSTM1 cause Paget's disease of bone. Calcif Tissue Int. 2006;78(5):271-277. doi: 10.1007/s00223-005-1299-6.

24. Leach RJ, Singer FR, Ench Y, Wisdom JH, Pina DS, Johnson-Pais TL. Clinical and cellular phenotypes associated with sequestosome 1 (SQSTM1) mutations. J Bone Miner Res. 2006;21(S2):P45-P50. doi: 10.1359/jbmr.06s208.

25. Blauwendraat $\mathrm{C}$, Wilke $\mathrm{C}$, Simón-Sánchez J, et al. The wide genetic landscape of clinical frontotemporal dementia: systematic combined sequencing of 121 consecutive subjects. Genet Med. 2018;20(2):240-249. doi: 10.1038/gim.2017.102.

26. Deng HX, Chen W, Hong ST, et al. Mutations in UBQLN2 cause dominant X-linked juvenile and adult-onset ALS and ALS/dementia. Nature. 2011;477(7363):211-215. doi: $10.1038 /$ nature 10353 .

27. Özoğuz A, Uyan Ö, Birdal G, et al. The distinct genetic pattern of ALS in Turkey and novel mutations. Neurobiol Aging. 2015;36(4):1764.e9-1764.e18. doi: 10.1016/ j.neurobiolaging.2014.12.032

28. Chang L, Monteiro MJ. Defective proteasome delivery of polyubiquitinated proteins by ubiquilin-2 proteins containing ALS mutations. PLoS One. 2015; 10(6): 0130162. doi: 10.1371 /journal.pone.0130162.

29. Kim SH, Stiles SG, Feichtmeier JM, et al. Mutation-dependent aggregation and toxicity in a Drosophila model for UBQLN2-associated ALS. Hum Mol Genet. 2018; 27(2):322-337. doi: $10.1093 / \mathrm{hmg} / \mathrm{ddx} 403$.
30. Dao TP, Martyniak B, Canning AJ, et al. ALS-linked mutations affect UBQLN2 oligomerization and phase separation in a position- and amino acid-dependent manner. Structure. 2019;27(6):937-951.e5. doi: 10.1016/j.str.2019.03.012.

31. Cirulli ET, Lasseigne BN, Petrovski S, et al. Exome sequencing in amyotrophic lateral sclerosis identifies risk genes and pathways. Science. 2015;347(6229):1436-1441. doi: $10.1126 /$ science.aaa3650.

32. Ye J, Cheung J, Gerbino V, et al. Effects of ALS-associated TANK binding kinase 1 mutations on protein-protein interactions and kinase activity. Proc Natl Acad Sci USA. 2019;116(49):24517-24526. doi: 10.1073/pnas.1915732116.

33. Hand CK, Mayeux-Portas V, Khoris J, et al. Compound heterozygous D90A and D96N SOD1 mutations in a recessive amyotrophic lateral sclerosis family. Ann Neurol. 2001;49(2):267-271. doi: 10.1002/1531-8249(20010201)49:2<267::aidana51>3.0.co;2-d.

34. Smith BN, Topp SD, Fallini C, et al. Mutations in the vesicular trafficking protein annexin A11 are associated with amyotrophic lateral sclerosis. Sci Transl Med. 2017; 9(388):eaad9157. doi: 10.1126/scitranslmed.aad9157.

35. Müller K, Brenner D, Weydt P, et al. Comprehensive analysis of the mutation spectrum in 301 German ALS families. J Neurol Neurosurg Psychiatry. 2018;89(8):817-827. doi: 10.1136/jnnp-2017-317611.

36. Teyssou E, Muratet F, Amador MDM, et al. Genetic screening of ANXA11 revealed novel mutations linked to amyotrophic lateral sclerosis. Neurobiol Aging. 2021;99: 102.e11-102.e20. doi: 10.1016/j.neurobiolaging.2020.10.015.

37. Liao D, Liao Q, Huang C, Bi F. Mutations of G38R and D40G cause amyotrophic lateral sclerosis by reducing Annexin A11 protein stability. Zhong Nan Da Xue Xue Bao Yi Xue Ban. 2018;43(6):577-582. doi: 10.11817/j.issn.1672-7347.2018.06.001.

38. Nahm M, Lim SM, Kim YE, et al. ANXA11 mutations in ALS cause dysregulation of calcium homeostasis and stress granule dynamics. Sci Transl Med. 2020;12(566): eaax3993. doi: 10.1126/scitranslmed.aax3993.

39. Li X, Jin Y, Yin Y. Allele frequency of pathogenic variants related to adult-onset Mendelian diseases. Clin Genet. 2019;96(3):226-235. doi: 10.1111/cge.13579.

40. Lowry JL, Ryan ÉB, Esengul YT, Siddique N, Siddique T. Intricacies of aetiology in intrafamilial degenerative disease. Brain Commun. 2020;2(2):fcaa120. doi: 10.1093/ braincomms/fcaa120. 


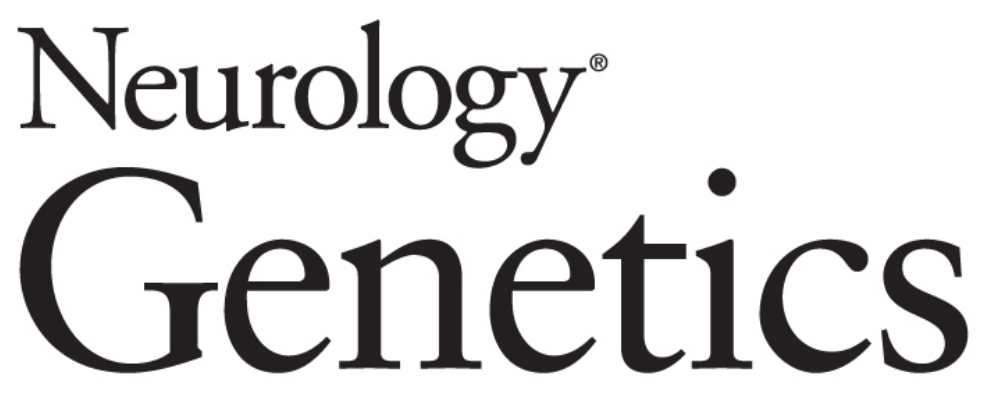

\section{Revealing the Mutational Spectrum in Southern Africans With Amyotrophic Lateral Sclerosis}

Melissa Nel, Amokelani C. Mahungu, Nomakhosazana Monnakgotla, et al. Neurol Genet 2022;8;

DOI 10.1212/NXG.0000000000000654

This information is current as of January 12, 2022

Neurol Genet is an official journal of the American Academy of Neurology. Published since April 2015, it is an open-access, online-only, continuous publication journal. Copyright Copyright @ 2022 The Author(s). Published by Wolters Kluwer Health, Inc. on behalf of the American Academy of Neurology.. All rights reserved. Online ISSN: 2376-7839.

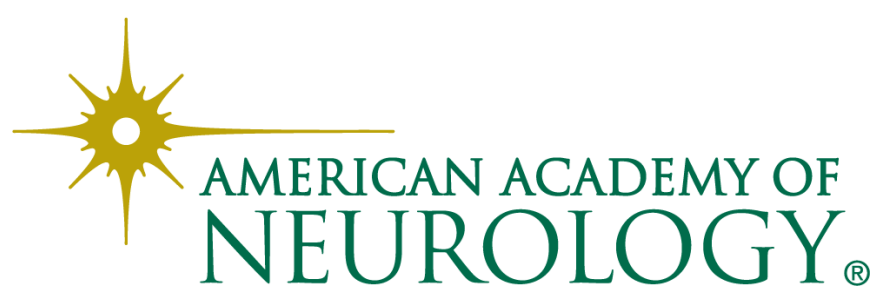




\section{Updated Information \& Services}

References

Citations

Subspecialty Collections

Permissions \& Licensing

Reprints including high resolution figures, can be found at: http://ng.neurology.org/content/8/1/e654.full.html

This article cites 40 articles, 7 of which you can access for free at: http://ng.neurology.org/content/8/1/e654.full.html\#\#ref-list-1

This article has been cited by 1 HighWire-hosted articles: http://ng.neurology.org/content/8/1/e654.full.html\#\#otherarticles

This article, along with others on similar topics, appears in the following collection(s):

\section{All Genetics}

http://ng.neurology.org//cgi/collection/all_genetics

Amyotrophic lateral sclerosis http://ng.neurology.org//cgi/collection/amyotrophic_lateral_sclerosis_ Inclusion, Diversity, Equity, Anti-racism, and Social Justice (IDEAS)

http://ng.neurology.org//cgi/collection/all_equity_diversity_and_inclusi on

\section{Underserved populations}

http://ng.neurology.org//cgi/collection/underserved_populations

Information about reproducing this article in parts (figures,tables) or in its entirety can be found online at:

http://ng.neurology.org/misc/about.xhtml\#permissions

Information about ordering reprints can be found online: http://ng.neurology.org/misc/addir.xhtml\#reprintsus

Neurol Genet is an official journal of the American Academy of Neurology. Published since April 2015, it is an open-access, online-only, continuous publication journal. Copyright Copyright ( 2022 The Author(s). Published by Wolters Kluwer Health, Inc. on behalf of the American Academy of Neurology.. All rights reserved. Online ISSN: 2376-7839.

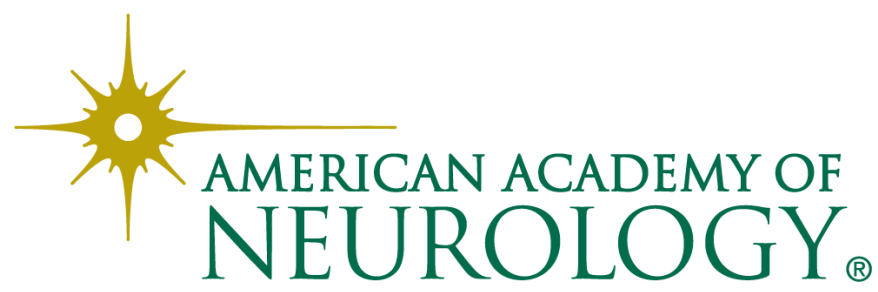

